\title{
a) STRATEGI PENGEMBANGAN SATWAS SDKP DALAM PENGAWASAN DAN PELAYANAN PUBLIK DI BRONDONG LAMONGAN JAWA TIMUR
}

\author{
Amira Bilhuda ${ }^{\mathrm{a}, *}$, Darmawan Ockto Sucipto ${ }^{\mathrm{a}}$, dan Gatut Bintoro ${ }^{\mathrm{a}}$ \\ ${ }^{a}$ Fakultas Perikanan dan Ilmu Kelautan, Universitas Brawijaya, Malang, Indonesia \\ ${ }^{*}$ Corresponding author : amirabilhuda6@gmail.com
}

\begin{abstract}
Abstrak
Satuan Kerja Pengawasan Sumberdaya Kelautan dan Perikanan Brondong berdiri pada tahun 2003 dan pada awal tahun 2017 berubah nama menjadi Satuan Pengawas Sumberdaya Kelautan Perikanan (Satwas SDKP) pada tahun 2017. Sistem pengawasan perikanan tangkap yang dilakukan oleh petugas Satwas SDKP terdiri dari pengawasan kapal perikanan, alat tangkap yang digunakan serta hasil tangkapan yang sesuai dengan peraturan perundang-undangan. Selain melakukan sistem pengawasan, Satwas SDKP juga menerbitkan Surat Layak Operasional sebagai salah satu syarat ketika nelayan akan melaut. Penelitian ini dilakukan pada bulan Februari sampai Maret 2017.Penelitian ini menggunakan metode deskriptif dengan survey.Metode analis is data yang digunakan adalah analis is SWOT dan analis is AHP (Analytical Hierarchy Proccess). Pelayanan publik yang disediakan oleh satwas SDKP antara lain penerbitan Surat Laik Operasional (SLO), Hasil Pemeriksaan Kapal (HPK) dan Verifikasi Pendaratan Ikan. Metode penelitian yang digunakan dalam penelitian ini adalah metode deskriptif dengan cara survey. Strategi kebijakan untuk meningkatkan pengawasan dan pelayanan public di Satwas SDKP Brondong adalah meningkatkan kerjasama dengan petugas Syahbandar, meningkatkan kualitas SDM Petugas SDKP, meningkatkan "sadar lapor" terhadap nelayan serta meningkatkan intensitas patroli laut
\end{abstract}

Kata Kunci: $A H P$, Satwas SDKP, SWOT

\begin{abstract}
Marine and fisheries resource monitoring work unit was established in 2003. Later on it changed tobe Monitoring Unit of Marine and Fisheries Resources in 2017. Fishing monitoring system done by Monitoring Unit of Marine and Fisheries Resources (MUMFR) consists of vessel document, fishing gear used, and legal fish landing. In addition to monitoring, MUMFR also publish operational proper latter as one of requirement when the fishermen will go to fish. This research was done from February to march in 2017. The research was used descriptive survey method. Methods used in this research were Strength Weakness Opportunities Threats (SWOT) and Analytical Hierarchy Process (AHP) analysis. Result showed that public services had to be provided by MUMFR such us publishing operational proper letter, ship checking report and verification report of fish landed. In order to increase MUMFR Brondong, strategy of policy have to be taken were increasing the human resource quality of MUMFR, upgrading the report aware fisherman, intensify the sea patrol, and escalate the partnership building with Syahbandar.
\end{abstract}

Keywords: AHP, Monitoring Unit Of Marine And Fisheries Resources, SWOT

\section{PENDAHULUAN}

\section{Latar Belakang}

Pelabuhan perikanan adalah tempat yang terdiri atas daratan dan perairan di sekitarnya dengan batasbatas tertentu sebagai tempat kegiatan pemerintahan dan kegiatan sistem bisnis perikanan yang dipergunakan sebagai tempat kapal perikanan bersandar, berlabuh, dan/atau bongkar muat ikan yang dilengkapi dengan fasilitas keselamatan pelayaran dan kegiatan penunjang perikanan [1].
Unit Pelaksana Teknis Pengawasan Sumber Daya Kelautan dan Perikanan, yang selanjutnya disebut UPT PSDKP, merupakan Unit Pelaksana Teknis Kementerian Kelautan dan Perikanan di bidang pengawasan sumber daya kelautan dan perikanan yang berada di bawah dan bertanggung jawab kepada Direktur Jenderal Pengawasan Sumber Daya Kelautan dan Perikanan. UPT PSDKP mempunyai tugas melaksanakan pengawasan sumber daya kelautan dan perikanan 
berdasarkan ketentuan peraturan perundangundangan [2].

Pengawas Perikanan adalah pegawai negeri sipil yang mempunyai tugas mengawasi tertib pelaksanaan ketentuan peraturan perundang-undangan di bidang perikanan[3].

Tugas Pengawasan Sumberdaya Perikanan dan Kelautan (PSDKP) adalah menerbitkan Surat Laik Operasi Kapal Perikanan, melakukan verifikasi pendaratan ikan dalam rangka penerbitan Sertifikat Hasil Tangkapan Ikan, memeriksa distribusi ikan impor, memeriksa kesesuaian jumlah dan jenis ikan dengan alat tangkap yang digunakan, memeriksa kesesuaian pelabuhan pangkalan dengan Surat Izin Penangkapan Ikan (SIPI) atau Surat Izin Kapal Pengangkut Ikan (SIKPI) dan memeriksa kesesuaian jumlah dan jenis ikan hidup hasil budidaya [4].

Nelayan yang berada disekitar PPN Brondong $80 \%$ masih menggunakan alat tangkap payang dan cantrang walaupun alat tangkap tersebut telah dilarang beroprasi.Peran Satuan Pengawasan Sumberdaya Kelautan dan Perikanan (Satwas SDKP) selaku individu atau kelompok yang memiliki kepentingan terhadap keputusan yang ditetapkan oleh pemerintah (Stakeholder) sangat diperlukan untuk menegakkan peraturan yang telah ditetapkan. Selain itu petugas juga harus meningkatkan kualitas pelayanan publik yang disediakan agar nelayan tetap melengkapi surat-surat yang harus dibawa saat melaut

\section{Perumusan Masalah}

Berdasarkan uraian di atas, rumusan masalah yang mendasari penelitian ini adalah sebagai berikut:

1. Apa saja strategi pengembangan untuk meningkatkan pengawasan dan pelayanan publik di Satwas SDKP Brondong?

2. Pihak mana saja yang berperan dalam peningkatan pengawasan dan pelayanan publik?

\section{Tujuan}

Tujuan dari penelitian tentang Strategi Pengembangan Satwas SDKP dalam pengawasan dan pelayanan publik di Brondong Jawa Timur adalah:

1. Menganalisis strategi pengembangan untuk meningkatkan pengawasan dan pelayanan publik di Satwas SDKP Brondong.

2. Menganalisis pihak mana saja yang berperan dalam peningkatan pengawasan dan pelayanan publik di Satwas SDKP Brondong.

\section{MATERI DAN METODE}

\section{Tempat dan Waktu}

Penelitian ini dilaksanakan pada bulan Februari - Maret 2017 di Satwas SDKP Brondong Lamongan Jawa Timur.

\section{Mate ri Penelitian}

Materi penelitian sebagai dasar penelitian yang meliputi hasil tangkapan yang didaratkan di PPN Brondong, data penerbitan dokumen kapal yang diterbitkan Satwas SDKP, peraturan perundang-undangan tentang perikanan serta analisis Strength, Weakness, Opportunity, threat (SWOT) dan Analytical Hierarchy Process (AHP) . Analisis SWOT berfungsi untuk mencari kebijakan apa saja yang akan diterapkan, dan AHP berguna untuk menghitumg prioritas kebijakan. Jadi, dua analisis ini akan membantu menemukan kebijakan apa saja yang mampu meningkatkan pengawasan dan pelayanan publik secara optimal.

\section{Metode dan Prosedur Pengambilan Data}

Metode yang digunakan dalam penelitian ini adalah metode deskriptif dengan carasurvey. Penelitian deskriptif adalah penelitian yang menggambarkan mengenai keadaan atau masalah yang ada yaitu sesuai apa adanya pada saat melakukan penelitian [5]. Sehingga tujuan dari penelitian menggunakan metode deskriptif ini adalah untuk membuat penjelasan secara sistematis, faktual, dan akurat mengenai fakta-fakta dan sifat populasi atau daerah tertentu. 
Metode survey adalah suatu metode pengumpulan data primer dengan memberikan beberapa pertanyaan kepada responden individu. Dengan demikian survey adalah teknik penelitian yang melalui pengamatan langsung terhadap suatu gejala dan biasanya dalam melakukan penelitian dengan menyebarkan kuisioner atau wawancara, dan biasanya dilakukan dalam penelitian kuantitatif maupun kualitatif. Bila perolehan data dengan cara menggunakan kuisioner atau wawancara, maka sumber data disebut responden. Namun jika sumber data berupa benda, gerak atau proses tertentu disebut teknik observasi. Dan apabila menggunakan dokumentasi, maka dokumen atau catatanlah yang menjadi sumber data [6] .

Wawancara merupakan suatu proses interaksi dan komunikasi dengan cara bertanya langsung kepada responden untuk mendapatkan informasi [7]. Jumlah responden yang diambil dalam penelitian ini sejumlah 60 orang untuk kuisioner SWOT dan 25 orang untuk kuisioner AHP yang terdiri dari petugas Satwas SDKP, Nelayan, Petugas Rukun Nelayan, Mahasiswa serta Dosen.

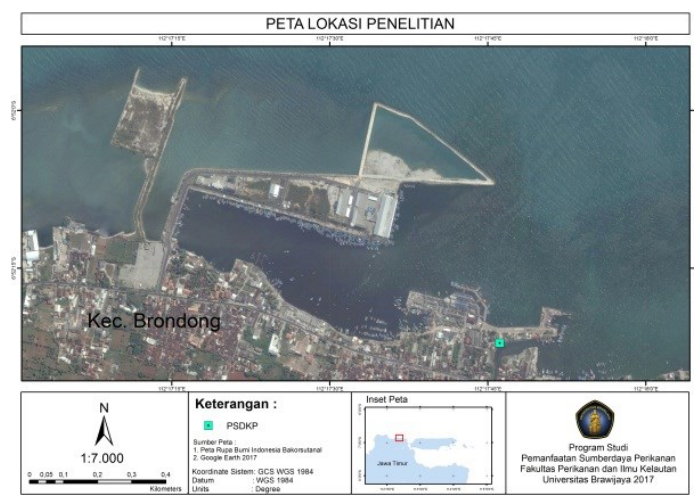

Gambar 1. Lokasi Penelitian

\section{HASIL DAN PEMBAHASAN}

Satuan Kerja Pengawasan Sumberdaya Kelautan dan Perikanan (PPN) Brondong yang berkedudukan di dalam kawasan Pelabuhan Perikanan Nusantara Brondong tepatnya di Kecamatan Brondong Kabupaten Lamongan berada pada titik koordinat $06^{\circ} 52^{\prime} 22^{\prime \prime}$ LS dan $112^{\circ} 17^{\prime} 46^{\prime}$ BT, lokasi ini sangat strategis sebagai salah satu unit pelaksana teknis Pengawasan Sumberdaya
Kelautan dan Perikanan karena posisinya yang tidak jauh dengan sentra-sentra Pendaratan dan Pendistribusian Hasil Perikanan di sepanjang pantai Utara laut Jawa dengan Wilayah kerja yang berbatasan langsung dengan Propinsi Jawa tengah yaitu kecamatan Bulu Kabupaten Tuban sampai dengan kecamatan Paciran Kabupaten Lamongan [8].

\section{Analisis SWOT}

Analisis SWOT digunakan untuk menentukan strategi optimalisasi Kekuatan dan Peluang serta untuk meminimalisir Kelemahan dan Ancaman[9]. Masing-masing strategi dibuat berdasarkan indikator-indikator yang ada.Kelemahan maupun Ancaman tidak hanya bertindak sebagai faktor penghambat, namun juga sebagai faktor pendukung.Dengan adanya Kelemahan dan Ancaman tersebut, maka pemanfaatan Kekuatan dan Peluang dapat dioptimalkan. Beberapa permasalahan dan isu yang terjadi di Satwas SDKP Brondong telah diketahui dan langkah selanjutnya adalah analisis faktor internal (kekuatan dan kelemahan) dan fator eksternal (peluang dan ancaman), matriks IFAS dan EFAS, grand strategi, dan langkah terakhir adalah matriks SWOT.

Dari hasil identifikasi faktor kekuatan dan kelemahan, kemudian disusun tabel Internal Strategic Anaysis Summary (IFAS) dan tabel Eksternal Strategic Anaysis Summary (EFAS) untuk menganalisis faktor internal dan eksternal dari perhitungan rating dan bobot dari masing-masing faktor dapat dilihat pada (Tabel 1).

Skoring faktor dimulai dari angka 1 hingga 4. Semakin tinggi skornya, berarti semakin tinggi pula pengaruh parameter tersebut terhadap peningkatan pengawasan dan pelayanan publik. Skoring ini digunakan untuk menentukan strategi mana yang akan diambil berdasarkan faktor- faktor internal Skoring ini digunakan untuk menentukan strategi mana yang akan diambil berdasarkan faktor- faktor internal Pada tabel 1, dapat kita ketahui bahwa nilai kekuatan tertinggi adalah variabel tingginya produksi serta nilai ekonomi ikan yang didaratkan yang didaratkan di PPN Brondong (0,1963). Pada 
faktor kelemahan tertinggi adalah variabel perbedaan lokasi tambat labuh yang akan mempersulit pengecekan kapal $(0,1730)$.

Posisi strategi digunakan untuk menentukan pilihan pada keempat strategi yang telah didapatkan dari hasil analisis matrik SWOT, yaitu dengan cara menempatkan total skor pada faktor internal dan eksternal matrik. Hasil dari kedua faktor internal (kekuatan dan kelemahan) dan faktor ekstrnal ( peluang dan ancaman) masing-masing dikurangi. Hasil dari masing - masing pengurangan faktor internal dan eksternal (S-W dan O-T)

Tabel 1. Analisis Skoring Faktor Internal

\begin{tabular}{|l|c|c|c|}
\hline Faktor Strategi Ke kuatan (S) & Bobot & Rating & Skor \\
\hline 1. Tingginya produksi ikan di PPN Brondong & 0,1963 & 4 & 0,7851 \\
\hline $\begin{array}{l}\text { 2. Tingginya jumlah ikan yang akan di ekspor } \\
\text { melalui PPN Brondong }\end{array}$ & 0,1795 & 3 & 0,5386 \\
\hline 3. Wilayah PPN yang strategis & 0,1777 & 4 & 0,7107 \\
\hline Jumlah & $\mathbf{0 , 5 5 3 5}$ & $\mathbf{1 1}$ & $\mathbf{2 . 0 3 4 4}$ \\
\hline \multicolumn{1}{|c|}{ Faktor strategi Kelemahan (W) } & & & \\
\hline 1. Banyaknya nelayan yang melanggar aturan & 0,1591 & 4 & 0,6363 \\
\hline $\begin{array}{l}\text { 2. Perbedaan lokasi tambat labuh yang akan } \\
\text { mempersulit pengecekan kapal }\end{array}$ & 0,1730 & 4 & 0,6921 \\
\hline 3. konflik antara nelayan lokal dan non lokal & 0,1144 & 3 & 0,3433 \\
\hline Jumlah & $\mathbf{0 , 4 4 6 5}$ & $\mathbf{1 1}$ & $\mathbf{1 , 6 7 1 6}$ \\
\hline
\end{tabular}

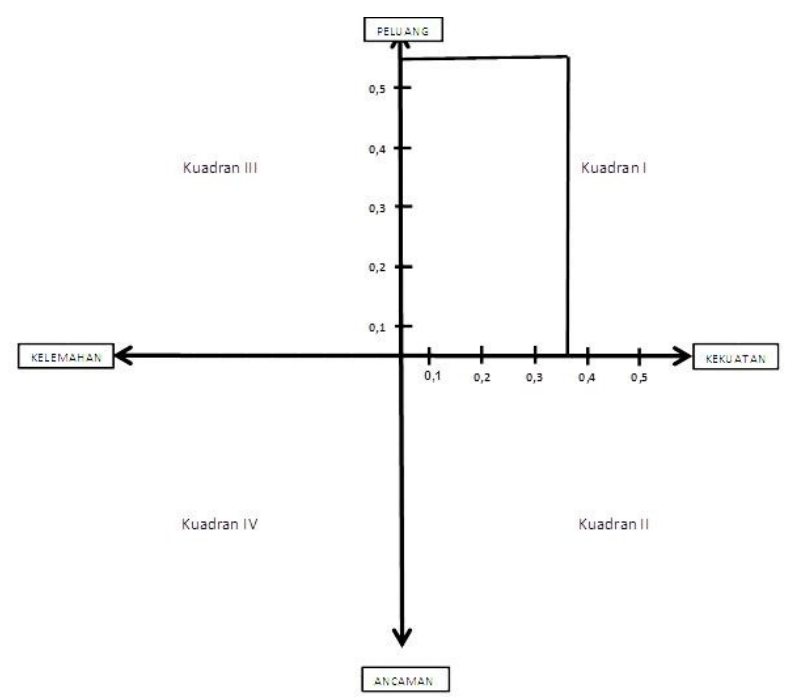

Gambar 2. Matriks Grand Strategi merupakan penentuan titik koordinat dalam menentukan strategi peningkatan pengawasan dan pelayanan publik. Berikut adalah perhitungan untuk men-cari titik koordinat dari sumbu $(\mathrm{X})$ dan sumbu $(\mathrm{Y})$ :

$$
\begin{aligned}
\mathrm{X} & =(\mathrm{S}-\mathrm{W}) \\
& =(2,0344-1,6716 \\
& =0,3628 \\
\mathrm{Y} & =(\mathrm{O}-\mathrm{T}) \\
& =(1,9613-1,3758) \\
& =0,5855
\end{aligned}
$$




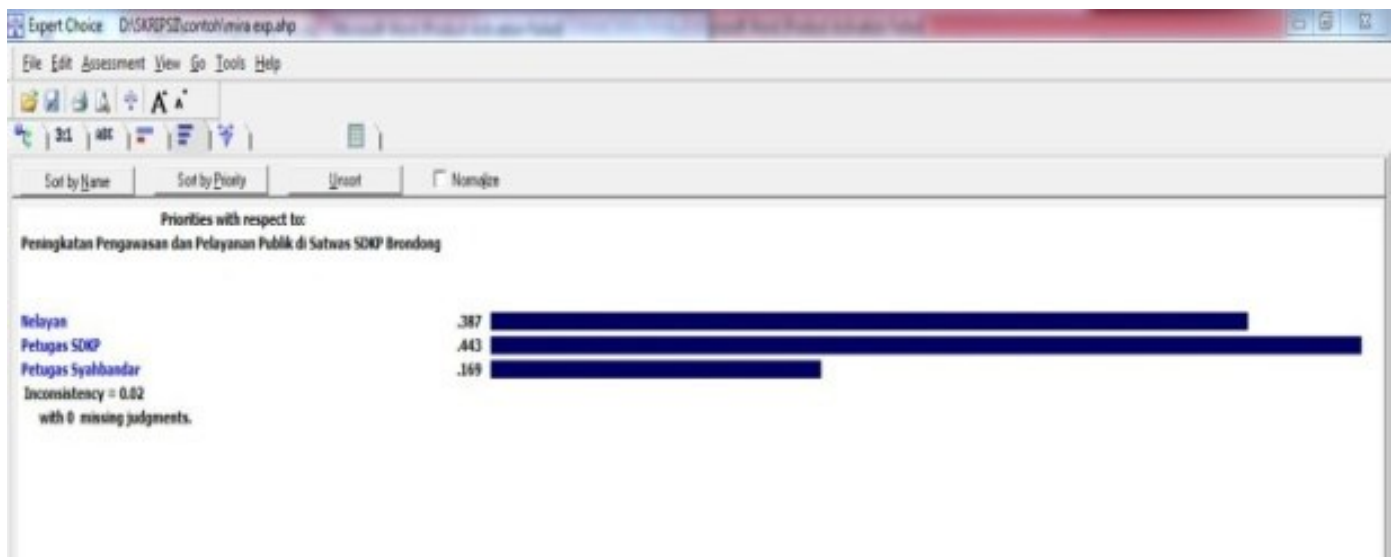

Gambar 3. Analisis Aktor dalam Mencapai Tujuan

Hasil perhitungan diatas diperoleh titik koordinat $(0,3628 ; 0,5855)$. Hal ini menunjukan Matriks Grand Strategi berada pada kuadran I (Gambar 1).

Berdasarkan analisis matrik grand strategi diperoleh bahwa peningkatan pengawasan dan pelayanan publik berada pada kuadran 1 yaitu pada kekuatan dan peluang (SO). Situasi ini menggambarkan peluang yang besar dalam mengoptimalkan peluang menurut kekuatan yang dimiliki, sehingga strategi yang harus diterapkan adalah mendukung peningkatan pengawasan. Strategi ini digunakan untuk meningkatkan pengawasan dan pelayanan publik di Satwas SDKP Brondong. Berikut ini adalah kebijakan yang dihasilkan oleh matriks SWOT (Tabel 1).

Strategi kebijakan tersebut adalah:

1) Meningkatkan kerjasama dengan petugas Syahbandar

2) Meningkatkan intensitas patroli laut

3) Faktor kebijakan dipengaruhi oleh Nelayan $(0,327)$

Namun, karena kebijakan yang dihasilkan matriks SWOT hanya dua, maka peneliti memasukkan seluruh kebijakan yang didapatkan dari matriks SWOT agar kebijakan yang ditawarkan kepada responden lebih banyak. Strategi kebijakan yang akan diolah di aplikasi Expert Choice antara lain :

1. Meningkatkan kerjasama dengan petugas Syahbandar

2. Meningkatkan kualitas SDM petugas SDKP

3. Meningkatkan sadar lapor terhadap nelayan

4. Meningkatkan intensitas patroli laut

\section{Analisis AHP}

\section{Hubungan aktor dengan tujuan utama}

Aktor memiliki peranan yang paling penting sebagai penentu dan pelaku utama dalam rencana peningkatan pengawasan dan pelayanan publik.Berdasarkan hasil analisis AHP dengan menggunakan Expert Choise 11 dari tiga aktor tersebut yang memiliki peran besar adalah petugas $\operatorname{SDKP}(0,443)$, terbesar kedua yaitu nelayan $(0,387)$ dan yang ketiga adalah petugas Syahbandar $(0,169)$. Inconsistensy Ratio (IR) yang didapat adalah sebesar 0,02 (Gambar 2). Hal ini menandakan bahwa dalam pembobotan ketiga aktor tersebut tidak terlalu konsisten, namun karena nilai $\mathrm{IR}=0,02$,jika nilai konsistensi $<0,10(10 \%)$ berarti jawaban pengguna konsisten, sehingga solusi yang dihasilkanpun optimal [10]

\section{Hubungan faktor dengan aktor}

Faktor-faktor yang terdapat pada peningkatan pengawasan dan pelayanan publik adalah ekonomi, kebijakan dan sosial.Ketiga faktor tersebut berhubungan dengan aktor sebelumnya yaitu nelayan, petugas SDKP dan petugas Syahbandar.

Berdasarkan hasil yang diperoleh dari tabel 17 didapatkan hasil prioritas sebagai berikut:

1. Faktor ekonomi sangat dipengaruhi oleh nelayan $(0,413)$ 
2. Faktor sosial sangat dipengaruhi oleh petugas SDKP dan Petugas Syahbandar $(0,493)$

Faktor kebijakan dipengaruhi oleh Nelayan $(0,327)$

Tabel 2.Nilai Hubungan Faktor dengan Aktor

\begin{tabular}{|c|c|c|c|}
\hline $\begin{array}{c}\text { Faktor } \\
\text { Aktor }\end{array}$ & $\begin{array}{c}\text { Ekon } \\
\text { omi }\end{array}$ & $\begin{array}{c}\text { Kebija } \\
\text { kan }\end{array}$ & $\begin{array}{c}\text { Sos } \\
\text { ial }\end{array}$ \\
\hline Nelayan & 0,413 & 0,327 & $\begin{array}{c}0,2 \\
66\end{array}$ \\
\hline $\begin{array}{c}\text { Petugas } \\
\text { SDKP }\end{array}$ & 0,196 & 0,311 & $\begin{array}{c}0,4 \\
93\end{array}$ \\
\hline $\begin{array}{c}\text { Petugas } \\
\text { Syahbandar }\end{array}$ & 0,196 & 0,311 & $\begin{array}{c}0,4 \\
93\end{array}$ \\
\hline
\end{tabular}

\section{a. Analis is Kebijakan AHP}

Kebijakan yang perlu diambil dalam peningkatan pengawasan dan pelayanan publik di Satwas SDKP Brondong berdasarkan hasil dari AHP menjelaskan bahwa aktor dengan bobot peran terbesar adalah petugas SDKP, karena dalam peningkatan pengawasan dan pelayanan publik petugas SDKP memperoleh skor tertinggi sebesar 0,443 atau 44,3\%. Jika keterlibatan petugas SDKP cukup banyak hal ini akan memudahkan meningkatkan
pengawasan.

Faktor sosial merupakan faktor yang sangat berpengaruh dalam peningkatan pengawasan dan pelayanan publik, karena berdasarkan hasil AHP ada dua aktor yang memeperoleh skor tertinggi pada faktor sosial, yakni 0,493 (tabel 2). Hal ini terjadi, sebab dalam pengawasan dan pelayanan publik dibutuhkan sosialisasi dan pendekatan ke nelayan. Dalam perhitungan AHP untuk penentuan prioritas strategi peningkatan sama dengan penentuan aktor maupun faktor, dengan menggunakan sistem berpasangan pada aplikasi Expert Choise 11, IR yang dihasilkan harus kurang dari $10 \%$.

Prioritas yang dihasilkan dari analisis AHP adalah :

1. Meningkatkan kualitas SDM petugas $\operatorname{SDKP}(27,5 \%)$.

2. Meningkatkan sadar lapor terhadap nelayan $(24,4 \%)$.

3. Meningkatkan intensitas patrol laut $(22.1 \%)$.

4. Meningkatkan kerjasama dengan petugas Syahbandar $(20,0 \%)$.

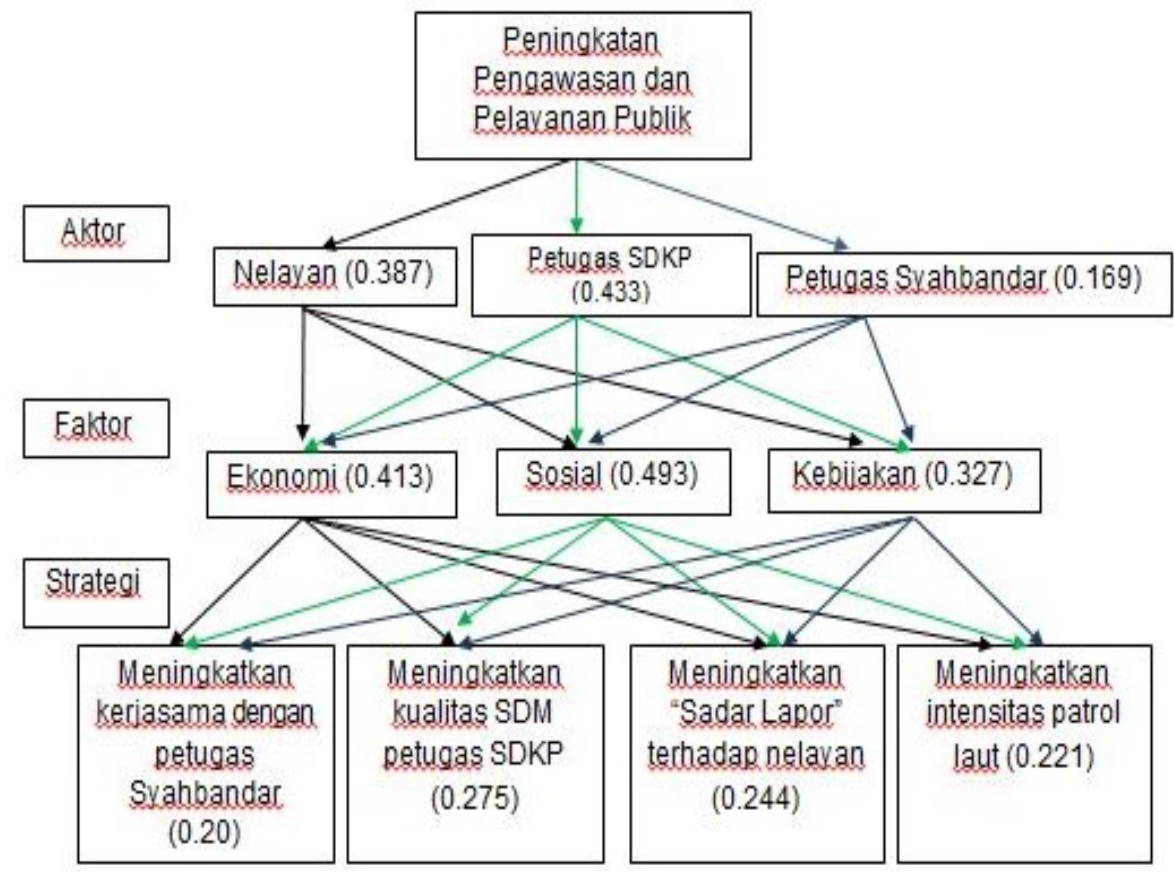

Gambar 4. Hasil Analisis Sensitivitas Aktor 


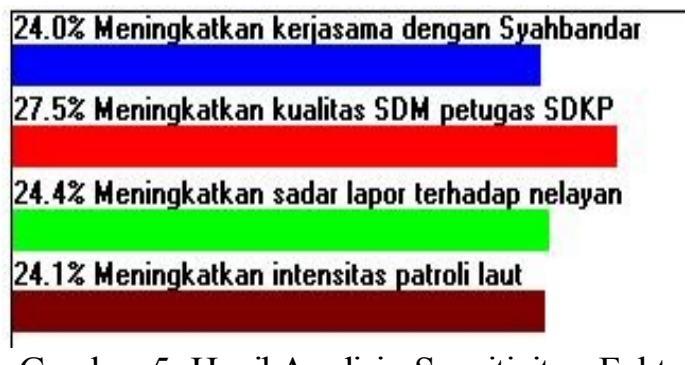

Gambar 5. Hasil Analisis Sensitivitas Faktor

\section{KESIMPULAN}

Dari hasil penelitian Strategi Peningkatan Satwas SDKP dalam bidang Pengawasan dan Pelayanan Publik di Brondong Lamongan Jawa Timur diperoleh hasil:

1. Strategi pada pengawasan dan pelayanan publik Satwas SDKP diperoleh pada kuadran 1 (Strategi S-O) yaitu menggunakan kekuatan dengan memnafaatkan peluang, sehingga strategi yang digunakan yakni meningkatkan intensitas patrol laut dan melakukan kerjasama dengan petugas Syahbandar untuk melakukan pengecekan ikan yang akan di ekspor.

2. Arahan kebijakan yang diprioritaskan untuk peningkatan pengawasan dan pelayanan publik di Satwas SDKP Brondong berdasarkan analisis AHP adalah meningkatkan kualitas SDM petugas SDKP $(27,5 \%)$, meningkatkan sadar lapor terhadap nelayan $(24,4 \%)$, meningkatkan intensitas patroli laut (24.1\%), meningkatkan kerjasama dengan Syahbandar $(24,0 \%)$.

3. Pihak yang berpengaruh dalam peningkatan pengawasan dan pelayanan publik berdasarkan analisis AHP adalah petugas SDKP $(0,443)$, nelayan $(0,387)$ dan pihak Syahbandar $(0,169)$.

\section{SARAN}

Saran yang bisa saya sampaikan adalah adanya penelitian lanjutan tentang kerjasama Satwas SDKP dengan PPDI PPN Brondong, karena masih banyak nelayan yang tidak memiliki ijin melaut namun diperbolehkan membeli bahan logistik di PPDI.

\section{DAFTAR PUSTAKA}

[1] Undang-undang Nomor 31 Tahun 2004 Tentang Perikanan

[2] Peraturan Menteri Kelautan dan Perikanan Nomor 33 tahun 2016 tentang Organisasi dan Tata Kerja Unit Pelaksana Teknis Pengawasan Sumberdaya Kelautan dan Perikanan

[3] Peraturan Menteri Kelautan dan Perikanan Nomor 45 tahun 2014 tentang Pelabuhan Perikanan

[4] Peraturan Menteri Kelautan dan Perikanan Nomor 17 Tahun 2014 Tentang Pelaksanaan Tugas Pengawas Perikanan. Jakarta

[5] Subandi. 2011. Deskripsi Kualitatif Sebagai Satu Metode Dalam Penelitian Pertunjukkan. Institut Seni Indonesia Surakarta. Surakarta. Jurnal Harmonia, Volume 11, no. 2.

[6] Arikunto, 2006. Prosedur Penelitian Suatu Pendekatan Praktik. Jakarta. Rineka Cipta

[7] Santoso, Gempur. 2005. Metodologi Penelitian (Kuantitatif dan Kualitatif). Prestasi Pustaka, Surabaya.

[8] Satuan Kerja Pengawasan Sumberdaya Perikanan. 2016. Laporan Tahunan. Brondong. Lamongan Jawa Timur a

[9] Setiadi,S, Amar, K, Aji, T., 2011. Penelitian Strategi Sustanability Usaha pada UKM Kuliner denganmenggunakan Metode SWOT- AHP. Teknik Industri. Universitas Islam Negeri Sunan Kalijaga.Yogyakart

[10] Padmowati. 2009. Pengukuran Index Konsistensi dalam Proses Pengambilan Keputusan menggunakan Metode AHP. Yogyakarta 